\section{THORACOSCOPY AND CAUTERIZATION.}

BY

BERNARD HUDSON, M.A., M.D.,

MEDICAL SUPERINTENDENT, VICTORIA SANATORIUM, DAVOS-PLATZ,

AND

G. MAURER, M.D.,

MEDICAL SUPERINTENDENT, GUARDAVAL SANATORIUM, DAVOS-DORF.

Is 1910, for the first time, Jacobaeus divided pleuiral adhesions by the galvanic cautery under the guidance of endoscopy. The results attained by earlier workers were far from encouraging, and even the procedure of Jacobaeus is not free from objection. That his operation is justified is clear from the results it has achieved; we criticize it, however, on the ground that after the pleural adhesions have been severed the incidence of tuberculous empyema, even of mixed bacterial infections, is very high. According to Jacobaeus and others who have used his operation, 10 per cent. of cases are followed by mixed bacterial empyema and 36 per cent. by tuberculous exudates, of which 15 per cent. are serious. Kremer and others have recently published statistics showing a somewhat smaller proportion of such infections of the pleural cavity. On the other hand, when there are no complications, improvement is obtained by means of this operation-according to Jacobaeus in 66 per cent. of cases, and according to Kremer in 63 per cent.

Recently one of us (G. M.) has elaborated a method of dividing pleural adhesions, especially those of considerable size, by means of a combination of the galvanic cautery with a prophylactic coagulation by diathermy. In this writer's series of cases only 1 per cent. with mixed bacterial empyema and 4 per ctit. with serious tuberculous exurlates have been observed; this represents a substantial reduction in the incidence of a dangerous complication.

The prophylactic diathermy is valuable for the following reasons. After the induction of artificial pneumothorax in cases of pulmonary tuberculosis the pleural surfaces are separated, adhesions between them being drawn out into the form of bands, which may consist either of lung tissue or of fibrous tissue, or, as is usually the case with adhesions of any size, of both. It is necessary to sever each adhesion as closely as possible to its parietal end and thus to prevent damaging the bronchial srstem and the lung tissue, and opening up the walls of cavities which may have been drawn into the adhesion. This procedure, which requires a considerable amount of technical skill, may be rendered very difficult by the rich supply of vessels usually found in the parietal portion of the adhesion, and, through the thoracoscope, seen clearly passing from the parietes into the adhesion. The danger of haemorrhage can, however, be almost completely eliminated by thoroughly coagulating the thoracic part of the adhesion with the diathermic cautery before severing it by means of the galvanic cautery. Attempts have been made to break down adhesions by the diathermic cautery alone; it has been found, however, that a current which is powerful enough to sever adhesions is likely also to produce dangerous internal reactions; indeed, in cases where the stumps are rather short the resulting necrosis may even reach the lung parenchyma, and eventually lead to the dreaded complication of emprema. We believe that diathermy used only to secure coagulation of vascular adhesions is a valuable procedure which lowers the incidence of complications and opens the way to still further development of Jacobaeus's original operation. The following case may serve to drmonstrate the possibility of this combined method.

The patient, a man aged 24, suffering from severe tuberculosis, had a daily rise of temperature up to $102^{\circ} \mathrm{F}$, and brought up each day about 2 oz. of muco-purulent sputum containing tubercle bacilli and elastic fibres in large quantities. The following radiographic appearances were ohserved after the induction of arlificial pneumothorax on the left side. Right side: a light veiling was seen in the upper part, and in the lower part there were numerous small soft shadows. Left side: the apex was diffusely clouded, the lung being apparently firmly fixed by adhesions.
Five months after the induction of pneumothorax an attempt was made to divide the adhesions on the left side by the combined method above described. Through the thoracoscope the pleural cavity was seen to be strongly vascular, the intercostal spaces and rib demarcation being clearly visible. The apex of the lung was fixed chicfly in the neighbourhood of the second rib by an adhesion about the thickness of a little finger. A thin transparent band was seen stretching to the front of the chest, and two others, each about the thickness of a lead pencil, stretched upwards and forwards from the lung to the chest wall. The patient stood the operation very well, having practically no reaction. His temperature gradually settled down, becomisg normal a week later, and he showed great improvement in general health. Three months later the cough and sputum had disappeared and a radiograph showed healing of the lesions on the right side and total collapse on the left side.

In this case, considering the technical difficulties involved in breaking down the coarse adhesions, complete thoracoplasty might have appeared to be the operation of choice; on account of the bilateral disease, however, and of the poor general condition of the patient, the plastic operation was ruled out, and the ultimate result in this case has proved to be very good.

\section{Attemoranda : \\ MEDICAL, SURGICAL, OBSTETRICAL. \\ TREATMENT OF PNEUMONIA BY CONVALESCENT SERUM.}

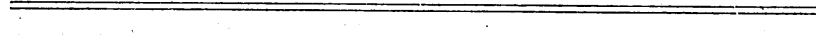

Tur following description of a case of influenzal pneumonia treated with convalescent serum is given in the hope that it may stimulate the application of similar treatment to further cases and so enable conclusions to be drawn as to the value of the procedure.

During the week ending February 2nd, a female patient, aged 34, had a sharp attack of influenza. After the temperature had been normal for a day it rose rapidly again with the development of central influenzal pneumonia. The sputum was rusty and blood-stained; signs were indefinite but suggestive of mainly left lower lobe involvement. Throughout the attack pleurisy was absent, and possibly on this account the respiration rate was little affected. At the end of the seventh day a rapid lysis set in and the temperature dropped to normal in thirty-six hours, with the usual amelioration of symptoms (February 11th).

While the patient's temperature was falling (February 10th) While the patient's temperature was falling (February 10th)
her child, a boy, aged a year and eleven months, became ill, and in two days (February 12th), he was obviously suffering from pneumonia. On February 13th, at 6 p.m., two days after his mother's temperature had reached normal, he was given $4 \mathrm{c.cm}$

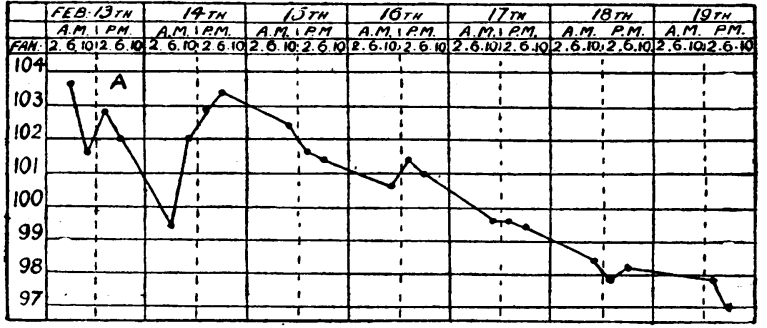

$A=4$ c.cm. Convalescent pneumonia serum.

of her serum subcutaneously, the blood having been taken four hours previously. He had been delirious during the day, and for three or four hours after receiving the dose of serum he had attacks of wild delirium separated by periods of disturbed. sleep. About 11 p.m. he became quiet and slept for the rest of the night. In the morning his temperature was $99.4^{\circ} \mathrm{F}$., a drop of nearly three degrees, his condition seemed much less toxic, and he began to take fluids with avidity. Though his temperature rose began to take fluids with avidity. Though his temperature rose
to $103.4^{\circ}$ the same evening, it began to drop from that point to $103.4^{\circ}$ the same evening, it began to drop from that point The respiration rate remained 50-60 till the temperature had reached normal, but the general condition never caused as much anxiety as it did before serum was given.

No bacteriological examinations of sputum were made, but it was concluded from the type of temperature in the case of the mother, and the absence of any tendency for it to recur after the rapid lysis, that infection was mainly pneumococcal.

A. Mclarex Ferrie, M.C., M.B., Ch.B., Donald E. Monley, M.D., B.S., D.P.H. 